\title{
Obesity and risk of ovarian cancer subtypes: evidence from the Ovarian Cancer Association Consortium
}

\author{
Catherine M Olsen ${ }^{1}$, Christina M Nagle ${ }^{1}$, David C Whiteman', Roberta Ness ${ }^{2}$, \\ Celeste Leigh Pearce ${ }^{3}$, Malcolm C Pike ${ }^{3,4}$, Mary Anne Rossing ${ }^{5}$, Kathryn L Terry ${ }^{6}$, \\ Anna H Wu ${ }^{3}$, The Australian Cancer Study (Ovarian Cancer) ${ }^{\mathbf{1}}$, Australian Ovarian Cancer \\ Study Group ${ }^{1,7}$, Harvey A Risch ${ }^{8}$, Herbert $\mathrm{Yu}^{9}$, Jennifer A Doherty ${ }^{5}$, \\ Jenny Chang-Claude ${ }^{10}$, Rebecca Hein ${ }^{10}$, Stefan Nickels ${ }^{10}$, Shan Wang-Gohrke ${ }^{11}$, \\ Marc T Goodman'2, Michael E Carney ${ }^{13}$, Rayna K Matsuno ${ }^{9}$, Galina Lurie ${ }^{9}$, \\ Kirsten Moysich $^{14}$, Susanne K Kjaer ${ }^{15,16}$, Allan Jensen ${ }^{15}$, Estrid Hogdall ${ }^{15}$, Ellen L Goode ${ }^{17}$, \\ Brooke L Fridley ${ }^{17}$, Robert A Vierkant ${ }^{17}$, Melissa C Larson ${ }^{17}$, Joellen Schildkraut ${ }^{18}$, \\ Cathrine Hoyo ${ }^{18}$, Patricia Moorman ${ }^{18}$, Rachel P Weber ${ }^{18}$, Daniel W Cramer ${ }^{6}$, \\ Allison F Vitonis ${ }^{6}$, Elisa V Bandera ${ }^{19}$, Sara H Olson ${ }^{4}$, Lorna Rodriguez-Rodriguez ${ }^{19}$, \\ Melony King ${ }^{20}$, Louise A Brinton ${ }^{21}$, Hannah Yang ${ }^{21}$, Montserrat Garcia-Closas ${ }^{22}$, \\ Jolanta Lissowska ${ }^{23}$, Hoda Anton-Culver ${ }^{24}$, Argyrios Ziogas ${ }^{24}$, Simon A Gayther ${ }^{3}$, \\ Susan J Ramus ${ }^{3}$, Usha Menon ${ }^{25}$, Aleksandra Gentry-Maharaj ${ }^{25}$, Penelope M Webb' \\ and on behalf of the Ovarian Cancer Association Consortium
}

${ }^{1}$ Queensland Institute of Medical Research, Royal Brisbane Hospital, Locked Bag 2000, Brisbane, Queensland 4029, Australia

${ }^{2}$ School of Public Health, University of Texas, Houston, Texas, USA

${ }^{3}$ Department of Preventive Medicine, Keck School of Medicine, University of Southern California, Los Angeles, California, USA

${ }^{4}$ Department of Epidemiology and Biostatistics, Memorial Sloan-Kettering Cancer Center, New York, New York, USA ${ }^{5}$ Program in Epidemiology, Fred Hutchinson Cancer Research Center, Seattle, Washington, USA

${ }^{6}$ Obstetrics and Gynecology Epidemiology Center, Brigham and Women's Hospital, Boston, Massachusetts, USA ${ }^{7}$ Peter MacCallum Cancer Centre, East Melbourne, Victoria, Australia

${ }^{8}$ Department of Epidemiology and Public Health, School of Medicine, Yale University School of Public Health, 60 College Street, New Haven, Connecticut, USA

${ }^{9}$ Cancer Epidemiology Program, University of Hawaii Cancer Center, Honolulu, Hawaii, USA

${ }^{10}$ Division of Cancer Epidemiology, German Cancer Research Center (DKFZ), Heidelberg, Germany

${ }^{11}$ Department of Obstetrics and Gynecology, University of Ulm, Prittwitzstrasse 43, 89075 Ulm, Germany

${ }^{12}$ Department of Biomedical Sciences, Cedars-Sinai Medical Center, Los Angeles, California, USA

${ }^{13}$ Department of Obstetrics and Gynecology, John A. Burns School of Medicine, University of Hawaii, Honolulu, Hawaii, USA

${ }^{14}$ Roswell Park Cancer Center, Buffalo, New York, USA

${ }^{15}$ Virus, Lifestyle and Genes, Danish Cancer Society Research Center, Copenhagen, Denmark

${ }^{16}$ Gynecologic Clinic, The Juliane Marie Centre, Rigshospitalet, University of Copenhagen, Copenhagen, Denmark

${ }^{17}$ Department of Health Sciences Research, Mayo Clinic College of Medicine, Rochester, Minnesota, USA

${ }^{18}$ Department of Community and Family Medicine, Duke University Medical Center, Durham, North Carolina, USA

${ }^{19}$ Robert Wood Johnson Medical School, The Cancer Institute of New Jersey, New Brunswick, New Jersey, USA

${ }^{20}$ School of Public Health, University of Medicine and Dentistry New Jersey, Piscataway, New Jersey, USA

${ }^{21}$ National Cancer Institute, 6120 Executive Boulevard, Rockville, Maryland, USA

${ }^{22}$ Division of Genetics and Epidemiology, Institute of Cancer Research, Belmont, Sutton, Surrey, UK

${ }^{23}$ Department of Cancer Epidemiology and Prevention, The M Sklodowska-Curie Cancer Center and Institute of Oncology, WH Roentgena 5, Warsaw, Poland

${ }^{24}$ Department of Epidemiology, School of Medicine, University of California, Irvine, California, USA

${ }^{25}$ Department of Gynaecological Oncology, EGA Institute for Women's Health, University College London, UK

Correspondence

should be addressed to C M Olsen

Email

catherine.olsen@qimr.edu.au http://erc.endocrinology-journals.org DOI: 10.1530/ERC-12-0395 (c) 2013 Society for Endocrinology Printed in Great Britain
Published by Bioscientifica Ltd 


\begin{abstract}
Whilst previous studies have reported that higher BMI increases a woman's risk of developing ovarian cancer, associations for the different histological subtypes have not been well defined. As the prevalence of obesity has increased dramatically, and classification of ovarian histology has improved in the last decade, we sought to examine the association in a pooled analysis of recent studies participating in the Ovarian Cancer Association Consortium. We evaluated the association between BMI (recent, maximum and in young adulthood) and ovarian cancer risk using original data from 15 case-control studies (13 548 cases and 17913 controls). We combined study-specific adjusted odds ratios (ORs) using a random-effects model. We further examined the associations by histological subtype, menopausal status and post-menopausal hormone use. High BMI (all time-points) was associated with increased risk. This was most pronounced for borderline serous (recent BMI: pooled $\mathrm{OR}=1.24$ per $\left.5 \mathrm{~kg} / \mathrm{m}^{2} ; 95 \% \mathrm{Cl} 1.18-1.30\right)$, invasive endometrioid $(1.17 ; 1.11-1.23)$ and invasive mucinous (1.19; $1.06-1.32)$ tumours. There was no association with serous invasive cancer overall $(0.98 ; 0.94-1.02)$, but increased risks for low-grade serous invasive tumours $(1.13,1.03-1.25)$ and in pre-menopausal women $(1.11 ; 1.04-1.18)$. Among post-menopausal women, the associations did not differ between hormone replacement therapy users and non-users. Whilst obesity appears to increase risk of the less common histological subtypes of ovarian cancer, it does not increase risk of high-grade invasive serous cancers, and reducing $\mathrm{BMI}$ is therefore unlikely to prevent the majority of ovarian cancer deaths. Other modifiable factors must be identified to control this disease.
\end{abstract}

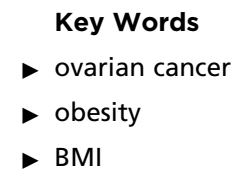

Endocrine-Related Cancer (2013) 20, 251-262

\section{Introduction}

It is widely accepted that being overweight or obese increases a woman's risk of developing endometrial and post-menopausal breast cancer (Calle \& Kaaks 2004). The association with ovarian cancer is less clear, largely because individual studies have had insufficient power to reliably detect moderate effects or to consider the different histological subtypes of ovarian cancer. In 2008, a pooled analysis of cohort studies concluded that BMI was associated with ovarian cancer in pre-menopausal women only, however this analysis only included 2000 cases and thus also had limited power to evaluate the different histological subtypes separately (Schouten et al. 2008). A recent pooled analysis conducted to overcome these limitations concluded that among women who have not used hormone replacement therapy (HRT), the risk of ovarian cancer increases by $10 \%$ for every $5 \mathrm{~kg} / \mathrm{m}^{2}$ increase in BMI (Collaborative Group on Epidemiological Studies of Ovarian Cancer 2012). This association did not vary significantly for the different histological subtypes of ovarian cancer, with the exception of borderline serous cancers where the excess relative risk (RR) was substantially greater than for the other tumour types. There was no increase in risk with increasing BMI among women who had used HRT.

However, the mean year of diagnosis of the cases in the studies included in the previous report was 1992 (Collaborative Group on Epidemiological Studies of Ovarian Cancer 2012) and over the last few decades, most countries have seen dramatic increases in the prevalence of overweight and obesity (Finucane et al. 2011). Classification of the different histological subtypes of ovarian cancer has also improved in recent years (Gilks \& Prat 2009) and it is possible that misclassification in earlier studies might have masked differences between the histological subtypes. In particular, it is now recognised that low- and high-grade invasive serous cancers are distinct entities and that many cancers previously described as high-grade endometrioid tumours should really be classified as high-grade serous cancers (Gilks \& Prat 2009). We therefore sought to confirm the results of the previous analysis in a second, independent pooled analysis using data from more recent studies that met the inclusion criteria for the Ovarian Cancer Association Consortium (OCAC) collaboration (Ramus et al. 2008).

Published by Bioscientifica Ltd. 
We examined the associations by histological subtype and tumour grade and by menopausal status and HRT use because, if the effects of obesity on ovarian cancer risk are mediated through oestrogenic pathways, then any association between BMI and risk may be more evident among women who have not used exogenous oestrogens. We also evaluated the relation between body size at different ages and ovarian cancer risk.

\section{Materials and methods}

OCAC was founded in 2005 to foster collaborative efforts in discovering and validating associations between genetic polymorphisms and ovarian cancer risk. A detailed description has been provided elsewhere (Ramus et al. 2008) but, briefly, studies were eligible for inclusion if they included at least 200 cases of ovarian cancer and 200 controls, with controls from broadly the same population as cases, and provided DNA for genetic analyses. Table 1 summarizes the characteristics of the 15 case-control studies (14 population-based and one clinic-based) that provided data for these analyses (Ziogas et al. 2000, Royar et al. 2001, Glud et al. 2004, Pike et al. 2004, Hoyo et al. 2005, Terry et al. 2005, Risch et al. 2006, Garcia-Closas et al. 2007, Rossing et al. 2007, Kelemen et al. 2008, Lurie et al. 2008, Merritt et al. 2008, Moorman et al. 2008, Wu et al. 2009, Balogun et al. 2011, Bandera et al. 2011, Ness et al. 2011). Race/ethnicity was categorised as nonHispanic White (88\%), Hispanic White (3\%), Black (4\%), Asian $(3 \%)$ or other $(2 \%)$. All studies had ethics approval, and all study participants provided informed consent.

\section{Analysis variables}

There was some variation in the way weight information was collected by the individual studies (Supplementary Table 1, see section on supplementary data given at the end of this article). Weight in early adulthood was reported by 14 studies (all except MAY); this was reported as weight at age 18 for nine studies and at age 20 for two studies (AUS and GER), while three studies reported weight 'in your 20s' (CON, MAL and USC). Recent weight was reported by 11 studies (AUS, CON, DOV, HOP, MAL, MAY, NCO, NJO, NEC, UCI and USC); for most studies this was reported as weight 1 year prior to diagnosis/reference date, but 5 years prior to diagnosis/reference date was used for four studies (CON, DOV, MAL and USC). To minimise overlap between our analyses of recent weight and the previous pooled analysis (The Collaborative Group on Epidemiological Studies of Ovarian Cancer 2012), we excluded two studies (GER and HAW) that were included in the previous analysis, but included two studies (NEC and USC) that had contributed only part of their data to the previous analysis (total overlap $\sim 1200$ cases). Maximum weight was reported by eight studies (AUS, DOV, GER, HAW, HOP, NCO, NJO and POL). BMI, calculated as weight in kilograms divided by the square of height in metres $\left(\mathrm{kg} / \mathrm{m}^{2}\right)$, was classified using the WHO definitions of obesity (<18.5 'underweight'; 18.5-24.9 'normal weight'; 25-29.9 'overweight'; 30-34.9 'class I obesity'; 35-39.9 'class II obesity' and $\geq 40$ 'class III obesity'; WHO 1995). For subgroup analyses there were small numbers in the upper classes of obesity for BMI in early adulthood, so these groups were combined.

\section{Covariate information}

Each case-control study provided information on potential confounding variables including age, cancer grade, race/ ethnicity, parity, breastfeeding, oral contraceptive (OC) and HRT use, family history of breast or ovarian cancer in a first-degree relative, menopausal status and history of hysterectomy or tubal ligation. All data were cleaned and checked for internal consistency and clarification was provided by the original investigators when needed.

\section{Statistical analysis}

We used Stukel's two-stage method of analysis to obtain study-specific odds ratios (ORs) and pooled ORs (pORs) and 95\% CIs (Stukel et al. 2001). In the first stage, each study was analysed separately, controlling for studyspecific confounders. The pooled exposure effect was estimated in a second stage using a meta-analytic approach. A weighted average of the log RR was estimated, taking into account the random effects using the method of DerSimonian \& Laird (1986). Statistical heterogeneity among studies was evaluated using Cochran's $Q$-test and $I^{2}$ statistics (Higgins \& Thompson 2002). All models were stratified by age in 5-year groups and adjusted for parity $(0,1,2,3,4+$ full-term births), OC use $(0, \leq 60$ and $>60$ months) and family history of breast or ovarian cancer in a first-degree relative. We also adjusted study-specific results for race/ethnicity (non-Hispanic White, Hispanic White, Black, Asian and other) where more than $10 \%$ of the study population was not classified as non-Hispanic White and inclusion of a term for race/ethnicity altered the OR by $10 \%$ or more. Other potential confounders considered but not included in final models since they did not make any material change to the BMI associations

Published by Bioscientifica Ltd. 


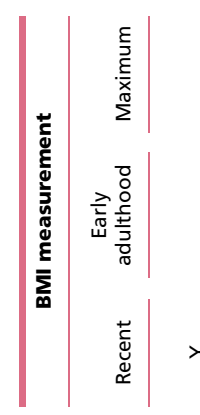

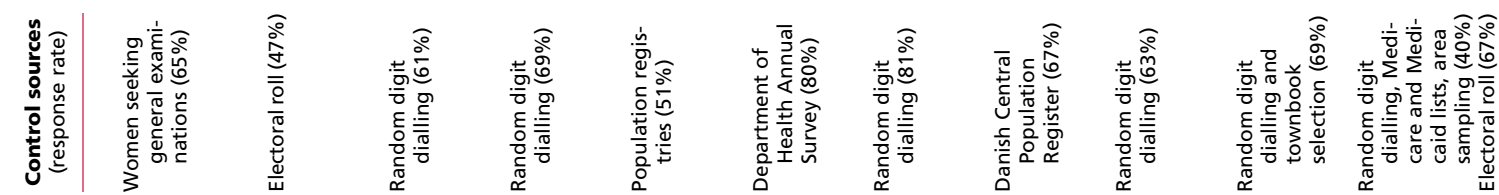

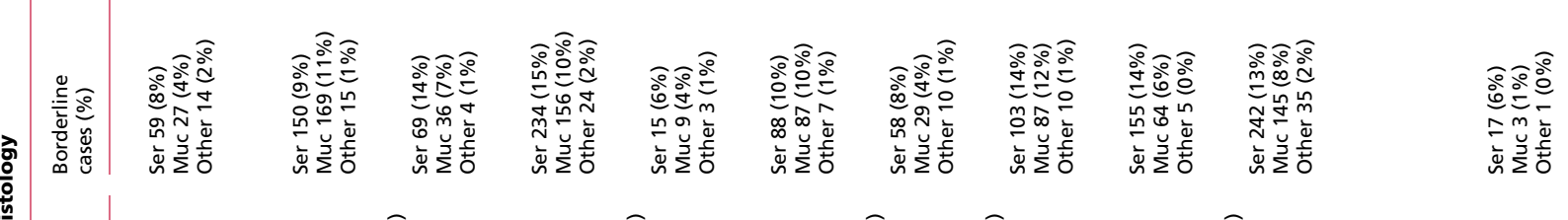

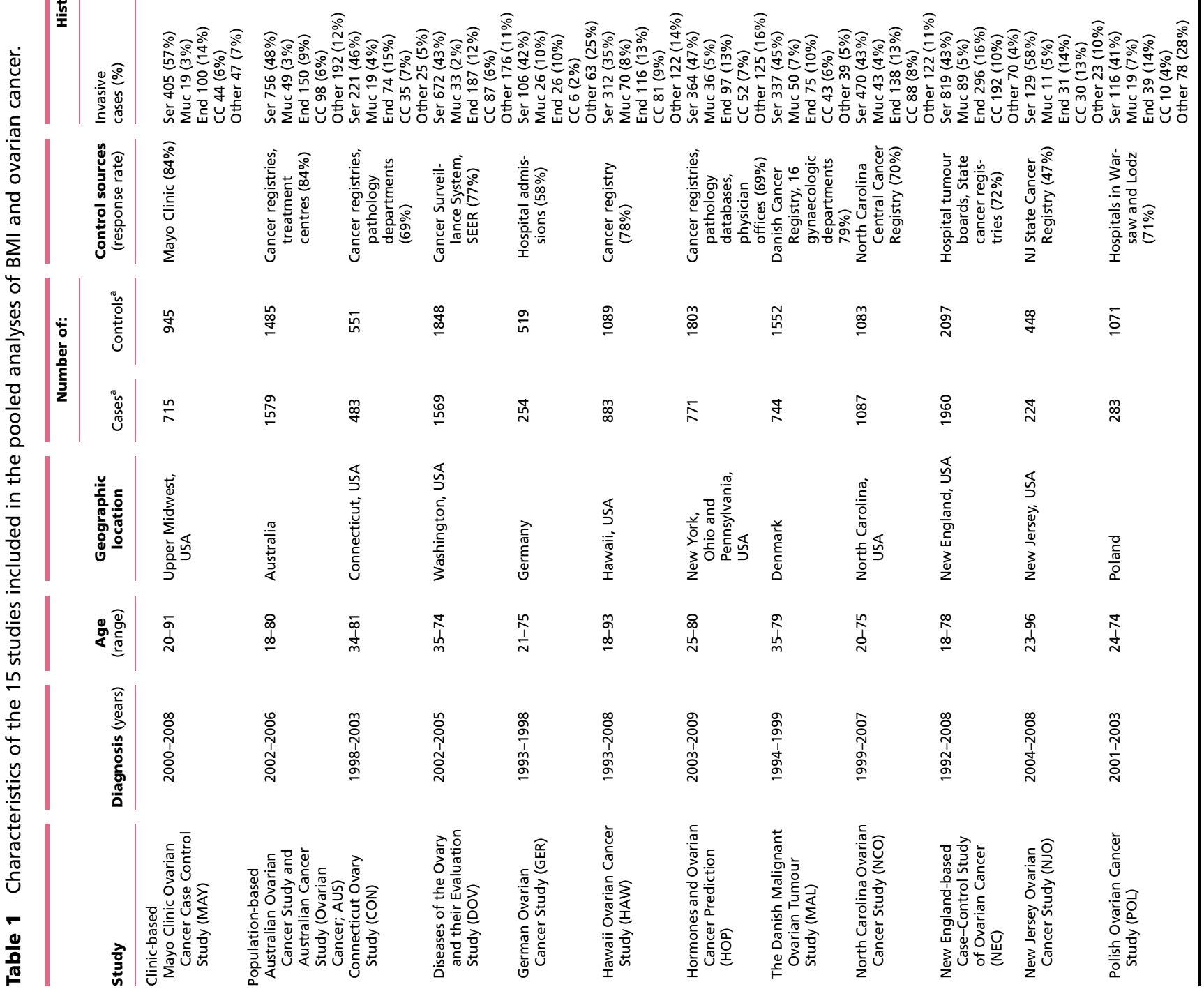



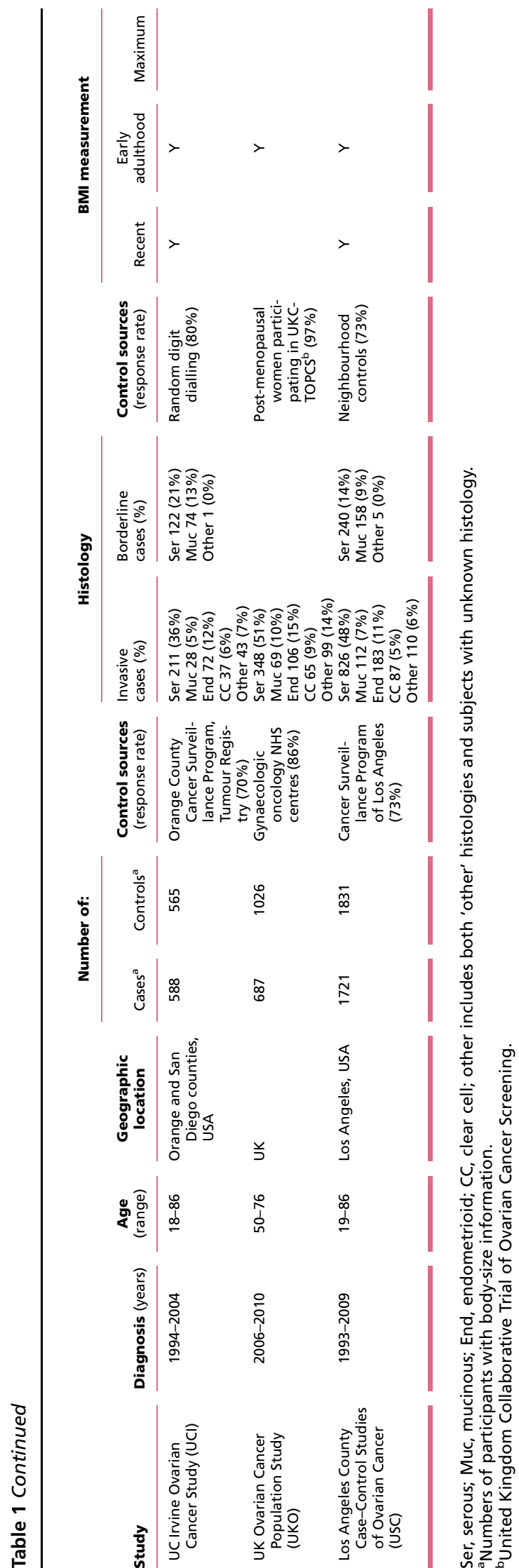

http://erc.endocrinology-journals.org DOI: 10.1530/ERC-12-0395

(c) 2013 Society for Endocrinology Printed in Great Britain were breastfeeding, history of hysterectomy, tubal ligation, menopausal status and HRT. Adjusting for history of endometriosis made no material change to the pooled estimates for the endometrioid or clear cell subtypes and thus it was not included in final models. Data on smoking status were not available for all studies, however including smoking status in models where it was available did not result in significant changes to the pooled estimates and thus it was not included in final models. Covariate data were mostly complete and uniformly coded for all studies with a few exceptions. The parity variable included all full-term births (live and still births) for all studies except MAY which recorded only live births. Secondly, tubal ligation and breastfeeding data were unavailable for the MAY study. These missing covariates were therefore not included in the first-stage models for this study.

We initially computed ORs for each of the primary exposure variables for invasive and borderline cancers separately and then further classified tumours by their histological subtype (serous, mucinous, endometrioid and clear cell). In the subtype-specific models, adjacent levels of confounders were collapsed where necessary to avoid zero cells in the two-stage models. Where heterogeneity was evident, we examined the data for potential sources of this heterogeneity including type of control group (population vs hospital-based) and style of questionnaire (self-completed vs in-person interview). The RR of ovarian cancer per $5 \mathrm{~kg} / \mathrm{m}^{2}$ increase in BMI was estimated by fitting a log-linear trend across categories of BMI $(18.5-<20,20-, 22.5-, 25-$, $27.5-, 30-, 32.5-, 35-, 37.5-, 40+\mathrm{kg} / \mathrm{m}^{2}$ ) using the overall median value within each category, except for the top category where we used the site-specific median as this varied between sites. Since we were interested in the effects of being overweight and speculated that the relation between BMI and cancer risk might not be linear at very low BMI levels, these analyses excluded women in the 'underweight' range (BMI $<18.5 \mathrm{~kg} / \mathrm{m}^{2}$ ).

We also conducted subgroup analyses to assess the interaction between recent BMI, menopausal status and use of any HRT (pre-/peri-menopausal, post-menopausal and never used HRT, post-menopausal and had used HRT). There was some heterogeneity in how menopausal status was defined across studies, so we also conducted analyses stratified by age at diagnosis ( $<50$ and $\geq 50$ years). To avoid problems with zero cells in some studies in these and other subgroup analyses, we pooled all data and computed ORs using logistic regression stratified by study site and age in 5-year groups in order to maximise the statistical power. The statistical significance of any observed

Published by Bioscientifica Ltd 
stratum-specific differences was then assessed by including a cross-product term (using the continuous BMI variables defined above) in regression models.

Analyses were conducted using SAS (SAS Institute, Cary, NC, USA) and Stata 10 (College Station, TX, USA).

\section{Results}

Eleven studies contributed to analyses of recent BMI, eight studies for maximum BMI and 14 studies for BMI in early adulthood (Table 1). Using the two-stage method of analysis, we observed significantly increased risks of both invasive and borderline ovarian cancers associated with higher BMI at all three time-points. The association was modest for invasive tumours with an increase in risk of $4 \%$ per $5 \mathrm{~kg} / \mathrm{m}^{2}$ for recent BMI and 8\% for BMI in early adulthood, but was stronger for borderline tumours with increases of $15-18 \%$ per $5 \mathrm{~kg} / \mathrm{m}^{2}$ for the different timepoints (Table 2).

Results of the pooled analyses stratified by histological subtype are presented in Tables 3 and 4 for invasive and borderline tumours respectively. Overall, risk of invasive serous cancer was not associated with any measure of BMI (Table 3). However, stratification by tumour grade (data available for $91 \%$ of cases) revealed positive associations between all measures of BMI and risk of low-grade (G1) invasive serous tumours $(\mathrm{OR}=1.13,1.18$ and 1.24 per $5 \mathrm{~kg} / \mathrm{m}^{2}$ for recent, maximum and young adult BMI respectively, all $P<0.01$ ) but not high-grade (G2-G4) tumours $(\mathrm{OR}=0.96,0.96$ and 0.98 respectively). Higher BMI (all BMI variables) was significantly associated with an increased risk of invasive endometrioid ovarian cancer. This association was restricted to low- and intermediategrade (G1 and G2) tumours (OR per $5 \mathrm{~kg} / \mathrm{m}^{2} 1.25,1.22$ and 1.20 for recent, maximum and young adulthood BMI respectively, all $P \leq 0.001)$ and was not seen for high-grade (G3 and G4) endometrioid cancers $(\mathrm{OR}=0.97,1.02$ and 0.90 respectively) (data on grade available for $93 \%$ of cases). The associations between BMI and invasive mucinous and clear cell cancers were less clear, with increased risks of both tumour types associated with high recent BMI and, for mucinous cancers, BMI in young adulthood, but not maximum BMI. The results for recent BMI were essentially unaltered when we restricted the

Table 2 Adjusted ${ }^{a}$ pooled ORs $(95 \% \mathrm{Cls})$ for ovarian cancer in relation to BMI, by tumour behaviour ${ }^{\mathrm{b}}$.

\begin{tabular}{|c|c|c|c|c|c|c|c|c|c|c|}
\hline \multirow[b]{2}{*}{ BMI $\left(\mathrm{kg} / \mathrm{m}^{2}\right)$} & \multicolumn{5}{|c|}{ Invasive } & \multicolumn{5}{|c|}{ Borderline } \\
\hline & Studies & $I^{2}(\%)$ & Cases & Controls & pOR $(95 \% \mathrm{Cl})$ & Studies & $I^{2}(\%)$ & Cases & Controls & pOR $(95 \% \mathrm{Cl})$ \\
\hline \multicolumn{11}{|l|}{ Recent BMI } \\
\hline$<18.5$ & 11 & 26.6 & 183 & 282 & $1.08(0.84-1.39)$ & 10 & 0.0 & 57 & 281 & $1.13(0.82-1.55)$ \\
\hline $18.5-24.9$ (ref) & 11 & & 4020 & 6796 & 1.0 & 10 & & 1080 & 6599 & 1.0 \\
\hline $25-29.9$ & 11 & 31.2 & 2500 & 4077 & $1.00(0.92-1.09)$ & 10 & 13.8 & 662 & 3930 & 1.23 (1.09-1.39) \\
\hline $30-34.9$ & 11 & 0.0 & 1166 & 1808 & $1.06(0.97-1.16)$ & 10 & 1.1 & 379 & 1741 & $1.61(1.40-1.85)$ \\
\hline $35-39.9$ & 11 & 1.7 & 511 & 692 & $1.21(1.07-1.38)$ & 10 & 0.0 & 150 & 672 & $1.68(1.37-2.06)$ \\
\hline$\geq 40$ & 11 & 0.0 & 383 & 503 & $1.22(1.05-1.41)$ & 9 & 0.0 & 137 & 486 & $1.96(1.57-2.46)$ \\
\hline Per $5 \mathrm{~kg} / \mathrm{m}^{2 \mathrm{c}}$ & 11 & 47.7 & & & $1.04(1.00-1.08)$ * & 9 & 0.0 & & & $1.18(1.14-1.23)$ \\
\hline \multicolumn{11}{|l|}{ Maximum BMI } \\
\hline$<18.5$ & 6 & 0.0 & 24 & 33 & $1.22(0.69-2.14)$ & 3 & 0.0 & 5 & 19 & $1.00(0.33-3.03)$ \\
\hline $18.5-24.9$ (ref) & 8 & & 1393 & 2683 & 1.0 & 7 & & 296 & 2548 & 1.0 \\
\hline $25-29.9$ & 8 & 6.2 & 1427 & 2566 & 1.02 (0.92-1.13) & 7 & 19.7 & 275 & 2409 & $1.13(0.91-1.41)$ \\
\hline $30-34.9$ & 8 & 0.0 & 823 & 1335 & $1.17(1.04-1.31)$ & 7 & 17.0 & 199 & 1236 & $1.58(1.24-2.03)$ \\
\hline $35-39.9$ & 8 & 60.2 & 388 & 592 & $1.29(0.99-1.68)$ * & 6 & 0.0 & 105 & 544 & $1.70(1.30-2.22)$ \\
\hline$\geq 40$ & 8 & 15.9 & 310 & 490 & $1.16(0.96-1.41)$ & 5 & 30.5 & 108 & 455 & $1.90(1.35-2.68)$ \\
\hline Per $5 \mathrm{~kg} / \mathrm{m}^{2 \mathrm{c}}$ & 8 & 45.3 & & & $1.06(1.01-1.11)$ & 7 & 35.8 & & & $1.17(1.08-1.26)$ \\
\hline \multicolumn{11}{|c|}{ BMI early adulthood } \\
\hline$<18.5$ & 14 & 0.0 & 1646 & 2931 & $0.94(0.88-1.01)$ & 12 & 13.0 & 416 & 2718 & $0.97(0.85-1.11)$ \\
\hline $18.5-24.9$ (ref) & 14 & & 7278 & 12364 & 1.0 & 12 & & 1819 & 11245 & 1.0 \\
\hline $25-29.9$ & 14 & 0.0 & 788 & 1151 & $1.12(1.01-1.24)$ & 11 & 0.0 & 248 & 983 & 1.27 (1.09-1.49) \\
\hline $30-34.9$ & 14 & 0.0 & 176 & 233 & $1.21(0.98-1.49)$ & 10 & 0.0 & 66 & 210 & $1.32(0.98-1.78)$ \\
\hline$\geq 35$ & 12 & 0.0 & 76 & 108 & $1.08(0.78-1.49)$ & 10 & 0.0 & 43 & 100 & $1.86(1.25-2.78)$ \\
\hline Per $5 \mathrm{~kg} / \mathrm{m}^{2 \mathrm{c}}$ & 14 & & & & $1.08(1.03-1.14)$ & 12 & & & & $1.15(1.08-1.24)$ \\
\hline
\end{tabular}

*Significant heterogeneity noted $(P$ value for heterogeneity $<0.05)$.

${ }^{a}$ Stratified by age in 5 -year groups and adjusted for parity $(0,1,2,3,4+$ full-term births), hormonal contraceptive use ( 0 , $\leq 60$ and $>60$ months), family history of breast or ovarian cancer in a first-degree relative and, where appropriate, race/ethnicity.

${ }^{b}$ Numbers may not sum to total because of missing data.

${ }^{c}$ Excludes women in the underweight range (BMI $<18.5 \mathrm{~kg} / \mathrm{m}^{2}$ ).

http://erc.endocrinology-journals.org DOI: 10.1530/ERC-12-0395
(C) 2013 Society for Endocrinology Printed in Great Britain
Published by Bioscientifica Ltd. 
Table 3 Adjusted $^{a}$ pooled ORs ( $95 \%$ Cls) for invasive ovarian cancer in relation to BMI, by histological subtype ${ }^{b}$.

\begin{tabular}{|c|c|c|c|c|c|c|c|c|c|c|}
\hline & \multirow[b]{2}{*}{ Studies $(n)$} & \multirow[b]{2}{*}{ Controls $(n)$} & \multicolumn{2}{|r|}{ Serous } & \multicolumn{2}{|r|}{ Mucinous } & \multicolumn{2}{|c|}{ Endometrioid } & \multicolumn{2}{|r|}{ Clear cell } \\
\hline & & & $\begin{array}{c}\text { Cases } \\
(n)\end{array}$ & pOR $(95 \% \mathrm{Cl})$ & $\begin{array}{c}\text { Cases } \\
(n)\end{array}$ & pOR $(95 \% \mathrm{Cl})$ & $\begin{array}{c}\text { Cases } \\
(n)\end{array}$ & pOR $(95 \% \mathrm{Cl})$ & $\begin{array}{c}\text { Cases } \\
(n)\end{array}$ & pOR $(95 \% \mathrm{Cl})$ \\
\hline Recent BMI & 11 & & & & & & & & & \\
\hline$<18.5$ & & 282 & 91 & $0.93(0.72-1.20)$ & 19 & $2.48(1.03-4.51)$ & 33 & $1.47(0.98-2.21)$ & 18 & $2.69(1.34-5.41)$ \\
\hline $18.5-24.9$ (ref) & & 6796 & 2475 & 1.0 & 207 & 1.0 & 592 & 1.0 & 353 & 1.0 \\
\hline $25-29.9$ & & 4077 & 1477 & $0.93(0.86-1.02)$ & 134 & $1.19(0.95-1.50)$ & 380 & $1.12(0.96-1.30)$ & 227 & $1.05(0.79-1.40) *$ \\
\hline $30-34.9$ & & 1808 & 665 & $0.94(0.84-1.05)$ & 68 & $1.48(0.92-2.37)$ * & 205 & $1.37(1.14-1.64)$ & 98 & $1.14(0.79-1.63)$ * \\
\hline $35-39.9$ & & 692 & 275 & $1.06(0.90-1.23)$ & 29 & $2.03(1.10-3.77)$ & 97 & $1.74(1.36-2.23)$ & 48 & $1.59(1.14-2.24)$ \\
\hline$\geq 40$ & & 503 & 170 & $0.89(0.74-1.08)$ & 29 & $2.70(1.76-4.16)$ & 82 & $1.86(1.42-2.24)$ & 37 & $1.58(1.04-2.40)$ \\
\hline Per $5 \mathrm{~kg} / \mathrm{m}^{2 \mathrm{c}}$ & & & & $0.98(0.94-1.02)$ & & $1.19(1.06-1.32)$ & & $1.17(1.11-1.23)$ & & $1.06(0.96-1.17)$ * \\
\hline Maximum BMI & 8 & & & & & & & & & \\
\hline $18.5-24.9$ (ref) & & 2683 & 793 & 1.0 & 86 & 1.0 & 177 & 1.0 & 120 & 1.0 \\
\hline $25-29.9$ & & 2566 & 787 & $0.93(0.73-1.17)$ * & 84 & $1.22(0.88-1.69)$ & 194 & $1.20(0.96-1.45)$ & 112 & $0.95(0.72-1.26)$ \\
\hline $30-34.9$ & & 1335 & 445 & $1.03(0.89-1.18)$ & 34 & $1.08(0.70-1.67)$ & 129 & $1.63(1.26-2.10)$ & 69 & $1.22(0.88-1.70)$ \\
\hline $35-39.9$ & & 592 & 199 & $1.18(0.81-1.72)$ * & 20 & $1.30(0.74-2.27)$ & 67 & $1.78(1.29-2.46)$ & 33 & $1.30(0.84-2.00)$ \\
\hline$\geq 40$ & & 490 & 147 & $0.98(0.68-1.41)$ * & 17 & $1.37(0.76-2.46)$ & 60 & $1.82(1.29-2.56)$ & 27 & $1.12(0.70-1.82)$ \\
\hline Per $5 \mathrm{~kg} / \mathrm{m}^{2 \mathrm{c}}$ & & & & $1.00(0.93-1.07)$ & & $1.05(0.94-1.17)$ & & $1.18(1.09-1.28)$ & & $1.04(0.95-1.13)$ \\
\hline Early adult & 14 & & & & & & & & & \\
\hline$<18.5$ & & 2931 & 918 & $0.94(0.86-1.03)$ & 102 & $0.94(0.74-1.19)$ & 243 & $0.93(0.80-1.09)$ & 164 & $1.08(0.83-1.39)$ \\
\hline $18.5-24.9$ (ref) & & 12364 & 4161 & 1.0 & 465 & 1.0 & 1121 & 1.0 & 648 & 1.0 \\
\hline $25-29.9$ & & 1151 & 401 & $1.04(0.92-1.18)$ & 54 & $1.20(0.88-1.64)$ & 150 & $1.33(1.10-1.62)$ & 64 & $1.05(0.75-1.45)$ \\
\hline $30-34.9$ & & 231 & 73 & $1.03(0.78-1.37)$ & 19 & $1.90(1.12-3.21)$ & 39 & $1.51(1.03-2.21)$ & 14 & $1.10(0.61-1.99)$ \\
\hline$\geq 35$ & & 110 & 36 & $1.15(0.75-1.76)$ & 7 & $2.18(0.96-4.95)$ & 18 & $1.85(1.05-3.24)$ & 6 & $2.73(1.08-6.88)$ \\
\hline Per $5 \mathrm{~kg} / \mathrm{m}^{2 \mathrm{c}}$ & & & & $1.02(0.95-1.10)$ & & $1.22(1.07-1.40)$ & & $1.14(1.04-1.25)$ & & $1.02(0.89-1.16)$ \\
\hline
\end{tabular}

*Significant heterogeneity noted $(P$ value for heterogeneity $<0.05)$.

${ }^{a}$ Stratified by age in 5-year groups and adjusted for parity (0, 1, 2, 3, 4+ full-term births), hormonal contraceptive use (0, $\leq 60$ and $>60$ months), family history of breast or ovarian cancer in a first-degree relative and, where appropriate, race/ethnicity; pooled across study sites using random effects models. ${ }^{b}$ Numbers may not sum to total because of missing data.

'Excludes women in the underweight range (BMI $<18.5 \mathrm{~kg} / \mathrm{m}^{2}$ ).

analysis to include only studies that assessed weight around 5 years prior to diagnosis to reduce potential bias due to recent weight loss in cases. Considering all nonserous invasive cancers together, the association with recent BMI remained significant after adjusting for maximum BMI or BMI in young adulthood, however after adjusting for recent BMI there was no association with either maximum BMI $(\mathrm{OR}=1.02,95 \%$ CI 0.95-1.11 per $5 \mathrm{~kg} / \mathrm{m}^{2}$ ) or BMI in young adulthood $(\mathrm{OR}=0.96,95 \%$ CI $0.86-1.08$ per $5 \mathrm{~kg} / \mathrm{m}^{2}$ ).

Increasing BMI (all BMI variables) was associated with increased risks of both borderline serous and mucinous ovarian cancers, with significant trends with increasing BMI that were stronger for borderline serous cancers $\left(20-25 \%\right.$ increase per $\left.5 \mathrm{~kg} / \mathrm{m}^{2}\right)$ than borderline mucinous cancers $\left(9-11 \%\right.$ per $5 \mathrm{~kg} / \mathrm{m}^{2}$; Table 4$)$.

Although there was some heterogeneity among studies for some of the pooled estimates, heterogeneity for the estimates per $5 \mathrm{~kg} / \mathrm{m}^{2}$ only reached statistical significance for recent BMI and risk of clear cell tumours and the combined group of all invasive tumours; sensitivity analyses by study design features suggested that no single factor could explain this observed heterogeneity.

When we combined all tumour types and stratified by ever use of HRT, we observed a significant association between BMI and cancer risk among women who had not used HRT (OR per $5 \mathrm{~kg} / \mathrm{m}^{2}=1.10$; 95\% CI 1.07-1.14) but no association among women who had used HRT (1.02; $0.97-1.07)$. However, we saw markedly different patterns of association when we considered pre- and postmenopausal women and the different histological subtypes of cancer separately (Table 5). When we stratified by menopausal status and use of HRT, we saw significant interaction for recent BMI and risk of invasive serous cancers $(P \leq 0.001)$. A significant trend of increasing risk with increasing BMI was observed in pre-menopausal women, with no association among post-menopausal women who had never used HRT, and a significant inverse association among those who had used HRT. Further stratification of the pre-menopausal group suggested that the positive association was stronger for $\mathrm{G} 1(\mathrm{OR}=1.34$, 95\% CI 1.14-1.59) but still statistically significant for G2-G4 tumours (OR=1.07, 95\% CI 1.00-1.15; $P<0.05)$. A similar pattern was seen in analyses of maximum BMI and BMI in young adulthood (data not shown), suggesting that the lack of a positive association among postmenopausal women was not simply an artefact due to recent weight loss among women with serous cancer. For all other invasive subtypes combined, the association was somewhat stronger among pre-menopausal women than

Published by Bioscientifica Ltd. 
Table 4 Adjusted ${ }^{a}$ pooled ORs ( $95 \%$ Cls) for borderline ovarian cancer in relation to BMI, by histological subtype.

\begin{tabular}{|c|c|c|c|c|c|c|}
\hline & \multirow[b]{2}{*}{ Studies $(n)$} & \multirow[b]{2}{*}{ Controls $(n)$} & \multicolumn{2}{|r|}{ Serous $^{b}$} & \multicolumn{2}{|r|}{ Mucinous $^{\mathrm{b}}$} \\
\hline & & & Cases $(n)$ & pOR $(95 \% \mathrm{Cl})$ & Cases $(n)$ & pOR $(95 \% \mathrm{Cl})$ \\
\hline Recent BMI & 10 & & & & & \\
\hline$<18.5$ & & 281 & 23 & $1.12(0.70-1.79)$ & 33 & $1.61(1.08-2.39)$ \\
\hline $18.5-24.9$ (ref) & & 6599 & 568 & 1.0 & 454 & 1.0 \\
\hline $25-29.9$ & & 3930 & 403 & $1.40(1.22-1.62)$ & 234 & $1.08(0.91-1.28)$ \\
\hline $30-34.9$ & & 1741 & 236 & $1.86(1.55-2.24)$ & 122 & $1.32(1.05-1.67)$ \\
\hline 35-39.9 & & 672 & 101 & $2.11(1.66-2.70)$ & 41 & $1.29(0.91-1.84)$ \\
\hline$\geq 40$ & & 486 & 85 & $2.23(1.69-2.94)$ & 41 & $1.68(1.16-2.43)$ \\
\hline Per $5 \mathrm{~kg} / \mathrm{m}^{2 \mathrm{c}}$ & & & & $1.24(1.18-1.30)$ & & $1.09(1.02-1.16)$ \\
\hline Maximum BMI & 7 & & & & & \\
\hline $18.5-24.9$ (ref) & & 2548 & 135 & 1.0 & 138 & 1.0 \\
\hline $25-29.9$ & & 2409 & 153 & 1.39 (1.00-1.93) & 113 & $0.99(0.75-1.30)$ \\
\hline $30-34.9$ & & 1236 & 115 & $2.00(1.51-2.65)$ & 78 & 1.39 (0.99-1.96) \\
\hline $35-39.9$ & & 544 & 66 & $2.40(1.71-3.38)$ & 35 & $1.26(0.68-2.32)$ \\
\hline$\geq 40$ & & 455 & 71 & $2.73(1.92-3.88)$ & 30 & $1.29(0.79-2.11)$ \\
\hline Per $5 \mathrm{~kg} / \mathrm{m}^{2 \mathrm{c}}$ & & & & 1.25 (1.17-1.34) & & $1.09(0.98-1.21)$ \\
\hline BMI early adulthood & 12 & & & & & \\
\hline$<18.5$ & & 2718 & 222 & $0.90(0.77-1.06)$ & 171 & $1.07(0.88-1.31)$ \\
\hline $18.5-24.9$ (ref) & & 11245 & 1034 & 1.0 & 699 & 1.0 \\
\hline $25-29.9$ & & 983 & 152 & $1.40(1.12-1.74)$ & 86 & $1.22(0.95-1.55)$ \\
\hline $30-34.9$ & & 210 & 40 & $1.48(1.03-2.14)$ & 26 & $1.57(1.00-2.47)$ \\
\hline$\geq 35$ & & 100 & 29 & $2.34(1.47-3.74)$ & 12 & $2.00(1.00-4.01)$ \\
\hline Per $5 \mathrm{~kg} / \mathrm{m}^{2 \mathrm{c}}$ & & & & $1.22(1.12-1.33)$ & & $1.11(0.99-1.24)$ \\
\hline
\end{tabular}

${ }^{a}$ Stratified by age in 5 -year groups and adjusted for parity $(0,1,2,3,4+$ full-term births), hormonal contraceptive use $(0, \leq 60$ and $>60$ months), family history of breast or ovarian cancer in a first-degree relative and, where appropriate, race/ethnicity; pooled across study sites using random effects models. ${ }^{b}$ Numbers may not sum to total because of missing data.

'Excludes women in the underweight range (BMI $\left.<18.5 \mathrm{~kg} / \mathrm{m}^{2}\right)$.

post-menopausal women but did not differ by HRT use among post-menopausal women. The association with borderline tumours did not vary by menopausal status or HRT use. When we stratified by age at diagnosis ( $<50$ and $\geq 50$ years) instead of menopausal status the results did not differ materially (data not shown).

\section{Discussion}

The results of our pooled analysis confirm that being overweight or obese is associated with an overall increased risk of both invasive and borderline ovarian cancers, however for invasive cancers this association appears to be restricted to the non-serous and low-grade serous subtypes. Furthermore, most of our risk estimates were very consistent with those from a previous pooled analysis (Collaborative Group on Epidemiological Studies of Ovarian Cancer 2012) with a strong increase in risk of borderline serous cancer ( $\mathrm{pOR} / \mathrm{RR}=1.24$ per $5 \mathrm{~kg} / \mathrm{m}^{2}$ in our analysis vs 1.29 in the previous report) and intermediate risks for clear cell (1.06 vs 1.05) and invasive (1.19 vs 1.15$)$ and borderline (1.09 vs 1.06$)$ mucinous cancers. Like the previous report, we saw no increase in risk of invasive serous cancer overall (0.98 vs 1.00$)$, however we did see an increased risk of low-grade invasive serous cancers $(\mathrm{OR}=1.13)$ which are now thought to arise via a different aetiological pathway from their high-grade counterparts. The only subtype for which our results differed appreciably was invasive endometrioid cancers where we saw a $17 \%$ increase in risk per $5 \mathrm{~kg} / \mathrm{m}^{2}$ overall, and a $25 \%$ increase after excluding high-grade endometrioid cancers which are likely to be misclassified as serous tumours (Gilks \& Prat 2009), compared with only an 8\% increase in the previous study (Collaborative Group on Epidemiological Studies of Ovarian Cancer 2012).

Since endometrioid ovarian tumours are histologically similar to endometrial cancer (Russell 1994), which is strongly associated with obesity (Crosbie et al. 2010), it seems plausible that obesity might also be a relatively strong risk factor for this subtype of ovarian cancer. The roughly $70-80 \%$ risk increases we observed even among the groups of women with highest BMI were, however, considerably lower than the ninefold risk previously reported for endometrial cancer (Crosbie et al. 2010). Historically, the histopathological classification of ovarian cancer cell types has only been modestly reproducible

Published by Bioscientifica Ltd. 
(Hernandez et al. 1984, Cramer et al. 1987, Sakamoto et al. 1994), and particularly problematic was the specific diagnosis of serous vs endometrioid carcinomas (Stalsberg et al. 1988). A recent development is the recognition that many carcinomas formally considered high-grade endometrioid are better classified as high-grade serous (Gilks \& Prat 2009, Kobel et al. 2010, Madore et al. 2010). When we excluded high-grade endometrioid tumours from our analysis the associations with BMI were considerably strengthened while, as for invasive serous cancers, we saw no association with high-grade endometrioid tumours. It is thus possible that misclassification of serous and endometrioid tumours may explain, in part, why a significant association between obesity and endometrioid ovarian cancers has not previously been consistently reported and why it was not observed in the previous large pooled analysis which included mostly older studies and did not consider tumour grade (Collaborative Group on Epidemiological Studies of Ovarian Cancer 2012). Time trends in the use of various regimens of HRT, as well as the increasing prevalence of obesity over calendar time, may also play a role.

As in the previous pooled analysis, we observed an association between increasing BMI and risk of borderline ovarian tumours, with the strength of the association somewhat stronger for serous than mucinous tumours. High BMI has been associated with benign ovarian tumours (Jordan et al. 2007), and there is evidence from epidemiological, histopathological and molecular studies that these borderline tumours may develop from benign tumours in a neoplastic progression (Jordan et al. 2006). Our finding that low-grade but not high-grade invasive serous tumours were also associated with BMI supports this theory of progression for low-grade serous cancers.

We can only speculate as to why we observed heterogeneity in the association between BMI and risk of invasive serous tumours between pre- and post-menopausal women, however this could not be explained by a higher proportion of G1 tumours in the pre-menopausal group. The endocrine consequences of obesity may have differential effects on the pathogenesis of serous ovarian cancer in pre- and post-menopausal women. Whilst postmenopausal obesity is associated with higher levels of endogenous oestrogen due to the synthesis of oestrogen in body fat (Key et al. 2001), in pre-menopausal women, obesity lowers sex hormone-binding globulin (Key et al. 2001, Tworoger et al. 2006) but does not significantly influence the levels of oestrogens and androgens as the

Table 5 Adjusted ${ }^{a}$ ORs $(95 \%$ Cls) for ovarian cancer in relation to recent BMI, by menopausal status and use of HRT.

\begin{tabular}{|c|c|c|}
\hline & Controls $(n)$ & Cases $(n)$ \\
\hline \multicolumn{3}{|c|}{ Pre-menopausal women } \\
\hline $18.5-24.9$ (ref) & 2049 & 484 \\
\hline $25-29.9$ & 919 & 272 \\
\hline $30-34.9$ & 417 & 121 \\
\hline $35-39.9$ & 152 & 55 \\
\hline $\begin{array}{l}\geq 40 \\
\text { Per } 5 \mathrm{~kg} / \mathrm{m}^{2 \mathrm{c}}\end{array}$ & 136 & 47 \\
\hline \multicolumn{3}{|c|}{ Post-menopausal women, no HRT } \\
\hline $18.5-24.9$ (ref) & 1343 & 652 \\
\hline $25-29.9$ & 1054 & 425 \\
\hline $30-34.9$ & 522 & 216 \\
\hline $35-39.9$ & 226 & 87 \\
\hline $\begin{array}{l}\geq 40 \\
\text { Per } 5 \mathrm{~kg} / \mathrm{m}^{2 \mathrm{c}}\end{array}$ & 157 & 61 \\
\hline \multicolumn{3}{|c|}{ Post-menopausal women who used HRT } \\
\hline $18.5-24.9$ (ref) & 1650 & 778 \\
\hline $25-29.9$ & 1123 & 440 \\
\hline $30-34.9$ & 480 & 183 \\
\hline $35-39.9$ & 167 & 75 \\
\hline $\begin{array}{l}\geq 40 \\
\text { Per } 5 \mathrm{~kg} / \mathrm{m}^{2 c}\end{array}$ & 111 & 23 \\
\hline
\end{tabular}

Invasive serous ${ }^{\mathrm{b}}$

\begin{tabular}{l} 
OR $(95 \% \mathrm{Cl})$ \\
\hline 1.0 \\
$1.23(1.03-1.47)$ \\
$1.21(0.96-1.54)$ \\
$1.50(1.07-2.10)$ \\
$1.43(0.99-2.06)$ \\
$1.11(1.04-1.18)$
\end{tabular}

1.0

$0.87(0.74-1.01)$

$0.93(0.77-1.12)$

$0.89(0.67-1.16)$

$0.87(0.63-1.21)$

$0.97(0.92-1.03)$

\section{0}

$0.86(0.75-1.00)$

$0.86(0.71-1.05)$

$1.08(0.78-1.45)$

$0.49(0.30-0.77)$

$0.92(0.87-0.98)$

\begin{tabular}{c} 
All oth \\
\hline \\
Cases $(n)$ \\
\hline \\
514 \\
275 \\
139 \\
76 \\
72 \\
\\
347 \\
312 \\
153 \\
67 \\
65 \\
\\
313 \\
221 \\
101 \\
31 \\
31
\end{tabular}

$1.26(1.06-1.51)$

$1.40(1.11-1.76)$

$1.78(1.30-2.45)$

$1.81(1.30-2.52)$

$1.17(1.11-1.24)$

1.0

$1.20(1.00-1.43)$

$1.24(0.99-1.55)$

1.24 (0.91-1.69)

$1.64(1.18-2.29)$

$1.10(1.03-1.17)$

\begin{tabular}{c} 
All b \\
\hline Cases $(n)$ \\
\hline \\
529 \\
254 \\
147 \\
65 \\
52 \\
\\
157 \\
124 \\
82 \\
30 \\
33 \\
\\
138 \\
112 \\
60 \\
20 \\
13 \\
\end{tabular}

1.0

$1.22(1.02-1.46)$

$1.63(1.30-2.05)$

$2.00(1.44-2.78)$

$1.76(1.22-2.53)$

1.19 (1.12-1.27)

1.0

$1.17(0.90-1.51)$

$1.60(1.19-2.16)$

$1.36(0.88-2.09)$

$2.12(1.37-3.29)$

$1.17(1.08-1.27)$

\section{0}

1.35 (1.03-1.76)

$1.64(1.18-2.28)$

1.67 (1.00-2.78)

$1.48(0.80-2.76)$ $1.16(1.05-1.28)$

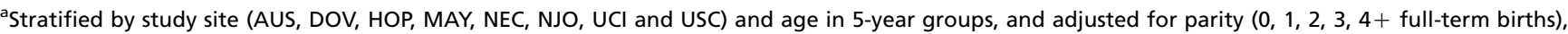
hormonal contraceptive use $(0, \leq 60$ and $>60$ months), family history of breast or ovarian cancer in a first-degree relative.

${ }^{b}$ Numbers may not sum to total because of missing data.

${ }^{c}$ Excludes women in the underweight range (BMI $<18.5 \mathrm{~kg} / \mathrm{m}^{2}$ ).

http://erc.endocrinology-journals.org DOI: 10.1530/ERC-12-0395
(C) 2013 Society for Endocrinology Printed in Great Britain
Published by Bioscientifica Ltd. 
ovaries produce more steroids than the peripheral fat tissue. Other hormonal factors that may mediate the relationship between obesity and risk of ovarian cancer include progesterone (Risch 1998) and insulin (Calle \& Kaaks 2004). Compared with women of 'normal' weight, pre-menopausal obese women have reduced serum progesterone levels due to an increase in anovulatory cycles (Key et al. 2001), and there is a significant body of evidence suggesting that progesterone plays a protective role in ovarian carcinogenesis (Risch 1998). Obesity is associated with increased insulin levels, which lead to increases in the insulin-like growth factor 1 (IGF1; Calle \& Kaaks 2004). There is no clear relation between adiposity and IGF1, however high levels of IGF1 have been associated with ovarian cancer in women younger than 55 years of age (Lukanova et al. 2002).

Our observation that the positive association with BMI was stronger among pre-menopausal women is consistent with the earlier analysis of cohort studies (Schouten et al. 2008). However, in contrast to the recent pooled analysis (Collaborative Group on Epidemiological Studies of Ovarian Cancer 2012), we found no suggestion of effect modification by use of HRT in post-menopausal women. Although the overall association did appear to be restricted to women who had never used HRT, this was driven by the stronger associations seen among premenopausal women who rarely use HRT. Similarly, the apparent lack of association among HRT users was driven by the strong inverse association with invasive serous cancers, the most common histological subtype, in this group. For the cancers that showed an overall association with BMI, non-serous invasive and borderline cancers, the risk estimates among post-menopausal women did not differ by use of HRT. Whilst data on recent or current use of menopausal hormonal therapy were not available for the current analyses, the possibility that recent use may modify the relationship between BMI and ovarian cancer risk deserves further exploration.

Strengths of our study include the large number of cases and controls made possible by pooling data from 15 individual case-control studies. Individual-level data were combined into a single dataset following a rigorous data cleaning and harmonisation protocol, giving enhanced ability to control for confounding in individual studies (Stukel et al. 2001). Pooling these data increased our statistical power to examine BMI in relation to the different histological subtypes of ovarian cancer, and allowed subgroup analyses to examine the effects by tumour grade, age, menopausal status, and for postmenopausal women, by use of HRT. Additionally, all studies contributing to the pooled analyses were conducted in the past two decades and, aside from early cases from the NEC and USC studies, a total of $\sim 1200$ cases $(10 \%)$, there was no overlap with the previous pooled analysis (Collaborative Group on Epidemiological Studies of Ovarian Cancer 2012). Histological misclassification is likely to be considerably less of a concern for these recent studies than in studies conducted in the more distant past, although some degree of misclassification remains likely.

However, as with any pooled analysis, some limitations must be acknowledged. First the majority of the studies included in the pooled analyses relied upon retrospective self-reports of weight and height. Research has shown that women with higher BMI are more likely to underestimate weight, whereas underweight women are more likely to overestimate body weight (KuskowskaWolk et al. 1989, Troy et al. 1995, Lawlor et al. 2002, Taylor et al. 2006); this may have attenuated the true associations. We cannot exclude the possibility of selection bias due to self-selection of more health conscious women, who are less likely to be overweight or obese, into control groups; this would have lead to overstated risk estimates. Such misclassification, however, is likely to be nondifferential with respect to the different histological subtypes. Finally, weight loss several years before the time of cancer diagnosis would, if present, bias risk estimates towards the null although the similar patterns of risk seen for all three measures of BMI, and for analyses of recent BMI restricted to studies that asked women to report their usual weight $\sim 5$ years prior to diagnosis, suggest that this has not occurred to any great extent.

In summary, obesity appears to moderately increase the risk of developing the less common histological subtypes of ovarian cancer, particularly borderline and low-grade invasive serous cancers and endometrioid cancers. With the possible exception of pre-menopausal women, it does not, however, appear to increase risk of the more common high-grade invasive serous cancers that account for the majority of ovarian cancer deaths.

\section{Supplementary data}

This is linked to the online version of the paper at http://dx.doi.org/10.1530/ ERC-12-0395.

\section{Declaration of interest}

The authors declare that there is no conflict of interest that could be perceived as prejudicing the impartiality of the research reported.

Published by Bioscientifica Ltd. 


\section{Funding}

This work was supported by donations by the family and friends of Kathryn Sladek Smith to the Ovarian Cancer Research Fund. The studies that contributed to this analysis were funded by the National Institutes of Health (grant numbers R01 CA13689101A1, CA14089, CA17054, CA61132, CA63464, N01 PC67010 and R03 CA113148 (for USC), R01 CA112523 and R01 CA87538 (for DOV), R01 CA58598, N01 CN67001 and N01 PC35137 (for HAW), 5R01 CA074850 and 5R01 CA080742 (for CON), R01 CA76016 (for NCO), R01-CA-122443 (for MAY), CA054419-10, P40 CA1005009 (for NEC), K07 CA095666, R01 CA83918 and K22 CA138563 CA58860 (for NJO), CA58860, CA92044 (for UCI) and RO1 CA61107 (for MAL); the California Cancer Research Program (grant numbers 0001389V20170 and 2110200 (for USC)); the California Department of Health Services (subcontract 050E8709 (for USC)); the UCIBCS component of this research (UCI) was supported by the National Institutes of Health (grant numbers CA58860, CA92044) and the Lon V Smith Foundation (grant number LVS39420); the German Federal Ministry of Education and Research of Germany, Programme of Clinical Biomedical Research (grant number 01GB9401), German Cancer Research Center and University of Ulm (for GER); the Eve Appeal, Oak Foundation, the University College Hospital, National Institute for Health Research Biomedical Research Centre and the Royal Marsden Hospital, Biomedical Research Centre (for UKO); the National Health and Medical Research Council of Australia (grant number 199600), US Army Medical Research and Materiel Command (grant numbers DAMD 170110729 and W81XWH0610220), Cancer Council Tasmania and Cancer Foundation of Western Australia (for AUS); the US Department of Defence (grant number W81XWH-10-1-0280 (for NEC)); the Cancer Institute of New Jersey (for NJO); Mermaid 1 and the Danish Cancer Society (for MAL); Intramural Research Funds of the National Cancer Institute, Department of Health and Human Services, USA (for POL).

\section{Acknowledgements}

We are grateful to the family and friends of Kathryn Sladek Smith for their generous support of the International OCAC through their donations to the Ovarian Cancer Research Fund. We thank all the individuals who took part in these studies and the project staff of all the participating studies. We thank Ursula Eilber and Tanja Koehler for their technical assistance for the German Ovarian Cancer study (GER). The Australian group gratefully acknowledges the contribution of all the clinical and scientific collaborators (see http://www.aocstudy.org). The Connecticut Ovary Study group gratefully acknowledges the cooperation of 30 Connecticut hospitals, including Stamford Hospital, in allowing patient access. The NJ Ovarian Cancer Study group gratefully acknowledges the contribution of collaborators and staff at the New Jersey State Cancer Registry, the Cancer Institute of New Jersey and Memorial Sloan-Kettering Cancer Center. The POCS thanks Drs Mark Sherman and Nicolas Wentzensen from the National Cancer Institute, USA, Drs Neonila Szeszenia-Dabrowska and Beata Peplonska of the Nofer Institute of Occupational Medicine (Lodz, Poland), Witold Zatonski of the Department of Cancer Epidemiology and Prevention, The M Sklodowska-Curie Cancer Center and Institute of Oncology (Warsaw, Poland), and Pei Chao and Michael Stagner from Information Management Services (Sliver Spring, MD, USA), for their valuable contributions to the study. Some of the data used in the CON Study were obtained from the Connecticut Tumor Registry, Connecticut Department of Public Health.

\section{References}

Balogun N, Gentry-Maharaj A, Wozniak EL, Lim A, Ryan A, Ramus SJ, Ford J, Burnell M, Widschwendter M, Gessler SF et al. 2011 Recruitment of newly diagnosed ovarian cancer patients proved challenging in a multicentre biobanking study. Journal of Clinical Epidemiology 64 525-530. (doi:10.1016/j.jclinepi.2010.07.008)

Bandera EV, King M, Chandran U, Paddock LE, Rodriguez-Rodriguez L \& Olson SH 2011 Phytoestrogen consumption from foods and supplements and epithelial ovarian cancer risk: a population-based case-control study. BMC Women's Health 11 40. (doi:10.1186/1472-6874-11-40)

Calle EE \& Kaaks R 2004 Overweight, obesity and cancer: epidemiological evidence and proposed mechanisms. Nature Reviews. Cancer 4 579-591. (doi:10.1038/nrc1408)

Collaborative Group on Epidemiological Studies of Ovarian Cancer 2012 Ovarian cancer and body size: individual participant meta-analysis including 25,157 women with ovarian cancer from 47 epidemiological studies. PLoS Medicine 9 e1001200. (doi:10.1371/journal.pmed. 1001200)

Cramer SF, Roth LM, Ulbright TM, Mazur MT, Nunez CA, Gersell DJ, Mills SE \& Kraus FT 1987 Evaluation of the reproducibility of the World Health Organization classification of common ovarian cancers. With emphasis on methodology. Archives of Pathology \& Laboratory Medicine 111 819-829.

Crosbie EJ, Zwahlen M, Kitchener HC, Egger M \& Renehan AG 2010 Body mass index, hormone replacement therapy, and endometrial cancer risk: a meta-analysis. Cancer Epidemiology, Biomarkers \& Prevention 19 3119-3130. (doi:10.1158/1055-9965.EPI-10-0832)

DerSimonian R \& Laird N 1986 Meta-analysis in clinical trials. Controlled Clinical Trials 7 177-188. (doi:10.1016/0197-2456(86)90046-2)

Finucane MM, Stevens GA, Cowan MJ, Danaei G, Lin JK, Paciorek CJ, Singh GM, Gutierrez HR, Lu Y, Bahalim AN et al. 2011 National, regional, and global trends in body-mass index since 1980: systematic analysis of health examination surveys and epidemiological studies with 960 country-years and 9.1 million participants. Lancet 377 557-567. (doi:10.1016/S0140-6736(10)62037-5)

Garcia-Closas M, Brinton LA, Lissowska J, Richesson D, Sherman ME, Szeszenia-Dabrowska N, Peplonska B, Welch R, Yeager M, Zatonski W et al. 2007 Ovarian cancer risk and common variation in the sex hormone-binding globulin gene: a population-based case-control study. BMC Cancer 7 60. (doi:10.1186/1471-2407-7-60)

Gilks CB \& Prat J 2009 Ovarian carcinoma pathology and genetics: recent advances. Human Pathology 40 1213-1223. (doi:10.1016/j.humpath. 2009.04.017)

Glud E, Kjaer SK, Thomsen BL, Hogdall C, Christensen L, Hogdall E, Bock JE \& Blaakaer J 2004 Hormone therapy and the impact of estrogen intake on the risk of ovarian cancer. Archives of Internal Medicine 164 2253-2259. (doi:10.1001/archinte.164.20.2253)

Hernandez E, Bhagavan BS, Parmley TH \& Rosenshein NB 1984 Interobserver variability in the interpretation of epithelial ovarian cancer. Gynecologic Oncology 17 117-123. (doi:10.1016/00908258(84)90065-9)

Higgins JP \& Thompson SG 2002 Quantifying heterogeneity in a metaanalysis. Statistics in Medicine 21 1539-1558. (doi:10.1002/sim.1186)

Hoyo C, Berchuck A, Halabi S, Bentley RC, Moorman P, Calingaert B \& Schildkraut JM 2005 Anthropometric measurements and epithelial ovarian cancer risk in African-American and White women. Cancer Causes \& Control 16 955-963. (doi:10.1007/s10552-005-3205-y)

Jordan S, Green A \& Webb P 2006 Benign epithelial ovarian tumours cancer precursors or markers for ovarian cancer risk? Cancer Causes \& Control 17 623-632. (doi:10.1007/s10552-005-0370-y)

Jordan SJ, Green AC, Whiteman DC \& Webb PM 2007 Risk factors for benign serous and mucinous epithelial ovarian tumors. Obstetrics and Gynecology 109 647-654. (doi:10.1097/01.AOG.0000254159.75977.fa)

Kelemen LE, Sellers TA, Schildkraut JM, Cunningham JM, Vierkant RA, Pankratz VS, Fredericksen ZS, Gadre MK, Rider DN, Liebow M et al. 2008 Genetic variation in the one-carbon transfer pathway and ovarian cancer risk. Cancer Research 68 2498-2506. (doi:10.1158/0008-5472. CAN-07-5165) 
Key TJ, Allen NE, Verkasalo PK \& Banks E 2001 Energy balance and cancer: the role of sex hormones. Proceedings of the Nutrition Society 60 81-89. (doi:10.1079/PNS200068)

Kobel M, Kalloger SE, Baker PM, Ewanowich CA, Arseneau J, Zherebitskiy V, Abdulkarim S, Leung S, Duggan MA, Fontaine D et al. 2010 Diagnosis of ovarian carcinoma cell type is highly reproducible: a transcanadian study. American Journal of Surgical Pathology 34 984-993. (doi:10.1097/ PAS.0b013e3181e1a3bb)

Kuskowska-Wolk A, Karlsson P, Stolt M \& Rossner S 1989 The predictive validity of body mass index based on self-reported weight and height. International Journal of Obesity 13 441-453.

Lawlor DA, Bedford C, Taylor M \& Ebrahim S 2002 Agreement between measured and self-reported weight in older women. Results from the British Women's Heart and Health Study. Age and Ageing 31 169-174. (doi:10.1093/ageing/31.3.169)

Lukanova A, Lundin E, Toniolo P, Micheli A, Akhmedkhanov A, Rinaldi S, Muti P, Lenner P, Biessy C, Krogh V et al. 2002 Circulating levels of insulin-like growth factor-I and risk of ovarian cancer. International Journal of Cancer 101 549-554. (doi:10.1002/ijc.10613)

Lurie G, Wilkens LR, Thompson PJ, McDuffie KE, Carney ME, Terada KY \& Goodman MT 2008 Combined oral contraceptive use and epithelial ovarian cancer risk: time-related effects. Epidemiology 19 237-243. (doi:10.1097/EDE.0b013e31816334c5)

Madore J, Ren F, Filali-Mouhim A, Sanchez L, Kobel M, Tonin PN, Huntsman D, Provencher DM \& Mes-Masson AM 2010 Characterization of the molecular differences between ovarian endometrioid carcinoma and ovarian serous carcinoma. Journal of Pathology $\mathbf{2 2 0}$ 392-400. (doi:10.1002/path.2659)

Merritt MA, Green AC, Nagle CM \& Webb PM 2008 Talcum powder, chronic pelvic inflammation and NSAIDs in relation to risk of epithelial ovarian cancer. International Journal of Cancer 122 170-176. (doi:10.1002/ijc.23017)

Moorman PG, Calingaert B, Palmieri RT, Iversen ES, Bentley RC, Halabi S, Berchuck A \& Schildkraut JM 2008 Hormonal risk factors for ovarian cancer in premenopausal and postmenopausal women. American Journal of Epidemiology 167 1059-1069. (doi:10.1093/aje/kwn006)

Ness RB, Dodge RC, Edwards RP, Baker JA \& Moysich KB 2011 Contraception methods, beyond oral contraceptives and tubal ligation, and risk of ovarian cancer. Annals of Epidemiology 21 188-196. (doi:10.1016/ j.annepidem.2010.10.002)

Pike MC, Pearce CL, Peters R, Cozen W, Wan P \& Wu AH 2004 Hormonal factors and the risk of invasive ovarian cancer: a population-based casecontrol study. Fertility and Sterility 82 186-195. (doi:10.1016/j.fertnstert.2004.03.013)

Ramus SJ, Vierkant RA, Johnatty SE, Pike MC, Van Den Berg DJ, Wu AH, Pearce CL, Menon U, Gentry-Maharaj A, Gayther SA et al. 2008 Consortium analysis of 7 candidate SNPs for ovarian cancer. International Journal of Cancer 123 380-388. (doi:10.1002/ijc.23448)

Risch HA 1998 Hormonal etiology of epithelial ovarian cancer, with a hypothesis concerning the role of androgens and progesterone. Journal of the National Cancer Institute 90 1774-1786. (doi:10.1093/jnci/ 90.23.1774)

Risch HA, Bale AE, Beck PA \& Zheng W 2006 PGR + 331 A/G and increased risk of epithelial ovarian cancer. Cancer Epidemiology, Biomarkers \& Prevention 15 1738-1741. (doi:10.1158/1055-9965.EPI-06-0272)
Rossing MA, Cushing-Haugen KL, Wicklund KG, Doherty JA \& Weiss NS 2007 Menopausal hormone therapy and risk of epithelial ovarian cancer. Cancer Epidemiology, Biomarkers \& Prevention 16 2548-2556. (doi:10.1158/1055-9965.EPI-07-0550)

Royar J, Becher H \& Chang-Claude J 2001 Low-dose oral contraceptives: protective effect on ovarian cancer risk. International Journal of Cancer 95 370-374. (doi:10.1002/1097-0215(20011120)95:6<370::AIDIJC1065 > 3.0.CO;2-T)

Russell P 1994 Surface epithelial-stromal tumors of the ovary. In Blaustein's Pathology of the Female Genital Tract, pp 705-782. Ed RJ Kurman., 4th edn New York: Springer-Verlag.

Sakamoto A, Sasaki H, Furusato M, Suzuki M, Hirai Y, Tsugane S, Fukushima M \& Terashima Y 1994 Observer disagreement in histological classification of ovarian tumors in Japan. Gynecologic Oncology 54 54-58. (doi:10.1006/gyno.1994.1165)

Schouten LJ, Rivera C, Hunter DJ, Spiegelman D, Adami HO, Arslan A, Beeson WL, van den Brandt PA, Buring JE, Folsom AR et al. 2008 Height, body mass index, and ovarian cancer: a pooled analysis of 12 cohort studies. Cancer Epidemiology, Biomarkers \& Prevention 17 902-912. (doi:10.1158/ 1055-9965.EPI-07-2524)

Stalsberg H, Abeler V, Blom GP, Bostad L, Skarland E \& Westgaard G 1988 Observer variation in histologic classification of malignant and borderline ovarian tumors. Human Pathology 19 1030-1035. (doi:10.1016/S0046-8177(88)80082-0)

Stukel TA, Demidenko E, Dykes J \& Karagas MR 2001 Two-stage methods for the analysis of pooled data. Statistics in Medicine 20 2115-2130. (doi:10.1002/sim.852)

Taylor AW, Dal Grande E, Gill TK, Chittleborough CR, Wilson DH, Adams RJ, Grant JF, Phillips P, Appleton S \& Ruffin RE 2006 How valid are self-reported height and weight? A comparison between CATI selfreport and clinic measurements using a large cohort study Australian and New Zealand Journal of Public Health 30 238-246. (doi:10.1111/ j.1467-842X.2006.tb00864.x)

Terry KL, De Vivo I, Titus-Ernstoff L, Shih MC \& Cramer DW 2005 Androgen receptor cytosine, adenine, guanine repeats, and haplotypes in relation to ovarian cancer risk. Cancer Research 65 5974-5981. (doi:10.1158/0008-5472.CAN-04-3885)

Troy LM, Hunter DJ, Manson JE, Colditz GA, Stampfer MJ \& Willett WC 1995 The validity of recalled weight among younger women International Journal of Obesity and Related Metabolic Disorders 19 570-572.

Tworoger SS, Eliassen AH, Missmer SA, Baer H, Rich-Edwards J, Michels KB, Barbieri RL, Dowsett M \& Hankinson SE 2006 Birthweight and body size throughout life in relation to sex hormones and prolactin concentrations in premenopausal women. Cancer Epidemiology, Biomarkers \& Prevention 15 2494-2501. (doi:10.1158/1055-9965.EPI-06-0671)

World Health Organisation (WHO) 1995 Physical status: the use and interpretation of anthropometry. Report of a WHO Expert Committee. World Health Organisation Technical Report Series 854 1-452.

Wu AH, Pearce CL, Tseng CC, Templeman C \& Pike MC 2009 Markers of inflammation and risk of ovarian cancer in Los Angeles County. International Journal of Cancer 124 1409-1415. (doi:10.1002/ijc.24091)

Ziogas A, Gildea M, Cohen P, Bringman D, Taylor TH, Seminara D, Barker D, Casey G, Haile R, Liao SY et al. 2000 Cancer risk estimates for family members of a population-based family registry for breast and ovarian cancer. Cancer Epidemiology, Biomarkers \& Prevention 9 103-111.

Received in final form 3 February 2013

Accepted 5 February 2013

Made available online as an Accepted Preprint

12 February 2013 http://erc.endocrinology-journals.org DOI: $10.1530 /$ ERC-12-0395
(C) 2013 Society for Endocrinology Printed in Great Britain
Published by Bioscientifica Ltd 